\title{
RINOTRAQUEITE VIRAL FELINA: RELATO DE CASO
}

CASTRO, Marines de

ISSUE DOI: $10.3738 / 1982.2278 .575$

\begin{abstract}
RESUMO: A infecção pelo Herpesvírus tipo 1 (FHV-1) é comum entre felinos. É uma doença de distribuição mundial e sinais clínicos como descargas nasais e oculares, espirros, tosse e dispnéia são frequentemente observados. A exposição a estas secreções é a principal forma de contaminação. Um gato macho, sem raça definida, de nove meses de idade foi apresentado para atendimento clínico Veterinário com histórico de secreção nasal, espirros, diminuição do apetite e cegueira. Após a instituição do tratamento a base de antibióticos e L-lisina houve uma melhora clínica observada nos primeiros cinco dias. O diagnóstico foi confirmado pela presença de corpúsculos de inclusão em material de raspado conjuntival. Decorridos vinte dias, o animal apresentava apenas raros episódios de espirros. A ocorrência deste caso de infecção pelo (FHV-1) deve servir como alerta para a ocorrência desta condição mórbida, como também, da importância da utilização da vacinação entre os pacientes felinos na região.
\end{abstract}

Palavras-chave: Herpesvírus tipo 1. Gato. Corrimento nasal. Conjuntivite. Vacinação.

\section{FELINE VIRAL RHINOTRACHEITIS: CASE REPORT}

\begin{abstract}
SUMMARY: Infection caused by Herpesvirus type 1 (FHV-1) is very common in felines. It is a worldwide-spread disease and clinical signs such as nasal and eye discharges, sneezing, coughing and dyspnea are frequently observed. The exposure to these secretions is the main means of contamination. A nine-month old indefinite-breed male cat was brought for veterinarian clinical care with medical history of runny nose, sneezing, lack of appetite and blindness. After the treatment based on antibiotics and L-lysine, there was clinical improvement which was observed within the five first days. The diagnostic was confirmed by the presence of inclusion bodies in material scraped from conjunctiva. After twenty days the animal presented only seldom sneezing episodes. The occurrence of this case of infection by (FHV-1) should serve as an alert not only to the occurrence of this morbid condition but also to the importance of the vaccination of feline patients in the region.
\end{abstract}

Keywords: Herpesvirus type 1. Cat, runny nose. Conjunctivitis. Vaccination

\section{INTRODUÇÃO}

A infecção pelo Herpesvírus tipo 1 (FHV-1) é comum entre felinos e extremamente contagiosa, resultando em sinais clínicos respiratórios e oculares severos (LAPPIN et al, 2002). É uma doença de distribuição mundial. o vírus pertence à família Herpesviridae subfamília Alphavirinae, gênero Varicellovirus (GASKELL et al. 2007). O calicivírus felino (CVF) juntamente com o FHV-1 constituem as duas principais causas de doença respiratória em gatos (GASKELL ; BENNET, 2001).

A exposição a secreções oronasais provenientes de gatos infectados é a principal forma de contaminação pelo FHV-1, estes animais podem eliminar grande quantidade de vírus nos corrimentos nasais e oculares e na saliva durante várias semanas (ETTINGER et al. 2004)

Durante a fase aguda da infecção observa-se febre, secreções nasais e oculares acentuadas, espirros, conjuntivite, tosse e dispnéia. O FHV-1 persiste como infecção crônica latente após a infecção primária, e pelo menos $80 \%$ dos gatos tornam-se portadores. A eliminação viral, ocorre por meio da secreção oral e nasal, se dá quando os animais são acometidos por outra doença concomitante, sofrem

\footnotetext{
${ }^{1}$ Medica Veterinária, doutoranda em Medicina Veterinária na área de Patologia Animal pela Universidade Estadual Paulista Júlio de Mesquita Filho UNESP-FCAV Câmpus de Jaboticabal. Professora do curso de Medicina Veterinária da FAI - Faculdades de Itapiranga. Endereço para correspondência: Departamento de Medicina Veterinária FAI - Faculdades, Rua Carlos Kummer, 100, Bairro Universitário, CEP: 89896000, Itapiranga, Santa Catarina, Brasil, e-mail: castrocati@yahoo.com.br
} 
qualquer episódio de estresse ou em locais onde se observa um grande numero de animais. A disseminação do vírus pode ser alta nos períodos de ativação viral, resultando em infecção a outros gatos. Conjuntivite recorrente, ceratite, espirro e secreção nasal são manifestações clínicas comuns nos animais que apresentaram reativação viral (carreadores crônicos). (GASKELL; BENNET, 2001; MAGGS; CLARKE, 2005; LAPPIN et al., 2002).

Entre os métodos diagnósticos mais utilizados destaca-se o PCR, isolamento viral, imunofluorescência direta e indireta e identificação de corpúsculos de inclusão em material de biópsia, suabe ou raspado nasal (de qual tecido?) (MAGGS; CLARKE, 2005). O PCR é o método mais específico e sensível para detectar a infecção pelo FHV-1, tanto em gatos infectados de modo agudo, como naqueles carreadores crônicos (ETTINGER et al., 2004). Infiltração neutrofílica, inflamação e necrose multifocal no epitélio oral, conjuntival e nasal são observados na histopatologia (BINNS et al., 2000).

As vacinas disponíveis apresentam efeitos satisfatórios no controle da doença, evitando o aparecimento dos sinais clínicos, entretanto, nenhuma vacina protege contra a infecção ou estado de portador (GASKELL et al., 2007). As vacinas atualmente disponíveis são compostas por vírus vivo modificado ou vírus inativado, combinando o FHV- 1, a outros agentes (panleucopenia, calicivirose, clamidiose e leucemia). Uma proteção menos efetiva poderá ser observada em alguns indivíduos vacinados sob circunstâncias particulares, como animais imunodeprimidos ou submetidos a desafio intenso (GASKELL et al., 2002). Recomenda-se vacinar com a primeira dose aos 53 dias de idade ( $9^{\circ}$ semana), seguida de uma segunda dose duas a quatro semanas após a primeira, com doses de reforço realizadas anualmente principalmente naqueles animais com acesso ao meio exterior e em contato com outros gatos,situação considerada de alto risco. Para aqueles animais que vivem sem contato com outros animais ou com o meio externo, a vacinação pode ser realizado num intervalo de três anos (LAPPIN et al. 2002)

Os cuidados de enfermagem tornam-se essenciais em animais com FHV-1, a reposição de fluidos, eletrólitos, manutenção do equilíbrio ácido-básico e utilização de sonda nasogástrica é de fundamental importância principalmente nos animais que não estão se alimentando. Geralmente devido à diminuição ou até mesmo ausência de sensação olfativa (congestão nasal presente) ou na presença de quadros ulcerativos na cavidade oral (o que leva à dor quando há alimento na boca), o paciente pode apresentar hipo ou até anorexia (GASKELL ; BENNET, 2001; BINNS et al., 2000). Na presença de descarga nasal, pode ser utilizada solução salina 0,9\% para limpeza, a qual deverá ser feita várias vezes ao dia, conforme a gravidade do caso, podendo também fazer uso da nebulização com descongestionantes nasais.

A utilização de antibióticos de largo espectro com boa penetração no trato respiratório são recomendados para o controle das infecções bacterianas secundárias, dentre eles cita-se a amoxicilina associado ao clavulanato de potássio. Os animais devem ser reexaminados quatro a cinco dias após o tratamento, e se necessário deve-se realizar cultura e antibiograma (GASKELL ; BENNET, 2001)

Diversos fármacos antivirais estão sendo testados em gatos com FHV-1, dentre eles o ganciclovir e o cidofovir parecem apresentar melhor eficácia em estudos in-vitro, podendo tornar-se útil para o uso clínico. Também o aciclovir quando utilizado em ceratites e conjuntivites várias vezes ao dia apresentou resultados satisfatórios (STILES, 2003). Apesar de poucos estudos clínicos, a utilização do interferon felino mostrou-se útil no controle das infecções respiratórias e lesões oculares (COLLINS, 2002).

A L-lisina também é recomendada como protocolo de tratamento para o FHV-1. A L-lisina é um antagonista da arginina, a qual é essencial para a replicação viral do FHV-1, em gatos. Esta medicação tem demonstrado efeitos inibitórios na replicação viral e na severidade dos sinais clínicos em pacientes que receberam suplementação oral (STILES, 2002).

O objetivo do presente trabalho é alertar para a ocorrência da rinotraqueite viral felina no oeste do estado de Santa Catarina.

Nucleus Animalium, v.4, n.1, maio 2012 


\section{RELATO DO CASO}

Em agosto de 2009, um gato macho, sem raça definida, de nove meses de idade foi apresentado para atendimento clínico veterinário no município de Faxinal dos Guedes/ SC, com histórico de secreção nasal, espirros e diminuição do apetite. A proprietária também informou que aos seis meses de idade o animal havia apresentado episódios de espirro com secreção nasal, porém, havia se recuperado. O paciente coabitava com outros animais e outros dois gatos apresentavam sintomatologia semelhante.

Ao exame físico foi observado apatia, membranas mucosas pálidas, escore corporal 3(3 de 9), descarga nasal mucopurulenta, ceratite (grave) bilateral com aparente cegueira e múltiplas úlceras de 0,3 $\mathrm{cm}$ de diâmetro na mucosa gengival.

Para confirmação diagnóstica solicitou-se exame para a identificação viral em material de raspado conjuntival. O resultado do exame citopatológico direto demonstrou os corpúsculos de inclusão virais do FHV-1.

O tratamento instituído foi a antibioticoterapia amoxicilina trihidratada e ácido clavulânico(Synulox®) 62,5 mg/Kg/VO(verificar dose ou unidade) duas vezes ao dia, e um suplemento alimentar rico em lisina Cat Lysin ${ }^{\circledR}$ 1,5 g/dia misturado no alimento, ambos prescritos durante 30 dias. Devido à presença de ulcerações na mucosa oral, foi prescrito alimento pastoso, (Recovery®) na primeira semana de tratamento. Decorridos cinco dias, avaliou-se novamente o animal e pode-se observar início da cicatrização das úlceras bucais e a diminuição da descarga nasal. Na oportunidade, a proprietária relatou que o paciente havia retomado seu apetite normal. Após 20 dias o animal apresentava aparente melhora dos sinais clínicos com apenas raros episódios de espirro.

\section{DISCUSSÃO}

Baseado nos sinais clínicos de acometimento do trato respiratório superior e pelo histórico clínico do animal chegou-se ao diagnóstico presuntivo de infecção pelo FHV-1, posteriormente confirmado pela presença de inclusões virais em material de suabe conjuntival. A preferência pela utilização deste método diagnóstico foi devido à praticidade em realizá-lo na área de ocorrência do caso.

Os sinais clínicos típicos da infecção pelo FHV-1 incluem ceratoconjuntivite e doença do trato respiratório superior (ETTINGER et al., 2004), achados estes observados no animal examinado. Segundo dados obtidos durante a anamnese, o animal coabitava com grande número de animais não vacinados e com contato à rua, fatores estes predisponentes à contaminação pelo FHV-1.

$\mathrm{O}$ protocolo medicamentoso apresentou bons resultados, constatados pela ausência dos sinais clínicos após 30 dias de tratamento. A dose de L-lisina foi de 1,5 g, ao dia, conforme recomendações do fabricante. Segundo Malik et al., (2009a) L-lisina apresentou bons resultados em gatos com FHV-1 em doses de $250 \mathrm{mg} /$ dia quando associada ao interferon felino, ou na dose de $1 \mathrm{mg}$ dia quando utilizada sozinha. REES ; LUBINSKI (2008) avaliando um grupo de 144 gatos de um abrigo para animais concluíram que, naqueles submetidos a condições de estresse, a L-lisina não foi eficiente na dose de 500 $\mathrm{mg} / \mathrm{dia}$, entretanto, os autores comentam sobre sua eficiência na utilização em gatos que vivem em casa.

Não foi recomendado o tratamento à base de fármacos antivirais no presente relato, embora estudos recentes realizados por Malik et al. (2009) demonstraram a eficácia do fanciclovir na diminuição dos sinais oculares (conjuntivite, ceratite e sequestro corneal) e da rinosinusite associada à infecção, além dos pacientes apresentarem boa tolerância ao fármaco . Pelo exposto, tal medicamento pode ser uma boa escolha para associação ao tratamento contra o FHV-1. O antibiótico de escolha para evitar infecções oportunistas do trato respiratório é a amoxicilina combinado com o ácido clavulânico. Malik et al. (2009) 
utilizaram enrofloxacina e clindamicina e Ettinger et al. (2004) recomendam a doxiciclina contra os agentes infecciosos secundários frequentes Chlamydophila, Mycoplasma e Bordetella.

A vacinação para o FHV-1 não evita completamente a infecção, mas é eficaz em reduzir os sinais clínicos da doença (ETTINGER et al., 2004). Foi recomendada à proprietária, a vacinação dos animais que não apresentavam sinais clínicos e que coabitavam com o paciente atendido.

O tratamento da ceratite e da conjuntivite causado pelo herpesvírus pode ser feito pelo uso de medicamentos antivirais tópicos, tais como a idoxuridina e vidarabina (ETTINGER et al., 2004). A trifluorotimidina não está licenciada para uso em gatos, mas apresenta bons resultados nas lesões. A utilização do aciclovir no tratamento tópico de ceratite, embora com informações conflitantes, demonstrou resultados satisfatórios em trabalho realizado por Willians et al. (2005), quando utilizaram a pomada tópica a $0,5 \%$ administradas 5 vezes ao dia. Os gatos, apesar da cegueira, conseguem viver bem em ambientes seguros (ETTINGER et al., 2004).

A diminuição das condições estressantes é um passo fundamental para gatos que vivem em gatis, pois o estresse contribui para a reativação viral e o aparecimento dos sinais clínicos das doenças. Também são importantes os cuidados sanitários para evitar a disseminação do vírus através de fômites (GASKELL et al., 2007).

\section{CONSIDERAÇÕES FINAIS}

A ocorrência deste caso de infecção pelo (FHV-1) deve servir como alerta para a ocorrência desta condição mórbida, como também, da importância da utilização da vacinação entre os pacientes felinos na região.

\section{REFERÊNCIAS}

BINNS, S.H.; SPEAKMAN, A.J.; HART, C.A. A study of feline upper respiratory tract disease with reference to prevalence and risk factors for infection with feline calicivirus and feline herpesvirus. Journal of Feline Medicine and Surgery, v.2, n.3, p.123-133, 2000.

COLLINS B.K. Treatment of feline ocular herpesvirus infections: a review. Advances in Small Medicine and Surgery, v. 15, n. 1, 2002.

ETTINGER, S.J.; FELDMAN, E.C. Tratado de Medicina Interna Veterinária. 5 ed. vol.1, Rio de Janeiro: Guanabara Koogan. 2004, 2256 p.

GASKELL, R.M.; BENNET, M. Doenças Infecciosas Felinas Tratado de Medicina de Pequenos Animais. São Paulo: Roca, 2001, 1075 p.

GASKELL R.M. Veterinary Products Committeeworking group report on feline and canine vaccination. The Veterinary Record, v. 134, p. 126-34, 2002.

GASKELL, R. Feline Herpesvírus. Veterinary Research, v. 38, p. 337-54, 2007.

LAPPIN, M.R. et al. Use of serologic tests to predict resistance to feline herpesvírus 1, feline calicivirus and feline parvovirus infection in cats. Journal of American Veterinary Medical Association, v. 220, p. 38-42, 2002.

MAGGS, D.J., CLARKE, H.E. Relative sensitivity of polymerase chain reaction assays used for detection of feline herpesvirus type 1 DNA in clinical samples and commercial vaccines. American Journal of Veterinary Residence, v.66, n.9, p.1550-1555, 2005. 
MALIK, R. et al. Treatment of feline herpesvirus - 1 associated disease in cats with famciclovir and related drugs. Journal of feline Medicine and Surgery, v. 11, p. 40-48, 2009.

REES, T. M.; LUBINSKI, T.L. Oral supplementation with L- lysine did not prevent upper respiratory infection in a shelter population of cats. Journal of feline Medicine and Surgery, v.10, p. 510-13, 2008.

STILES J.et al. Effect of oral administration of L-lysine on conjunctivitis caused by feline herpesvirus in cats. American Journal of Veterinary Research, v. 63, p. 99-103, 2002.

STILES J. Feline herpesvirus. Clinical Techniques in Small Animal Practice, v. 18, p. 178-85, 2003.

WILLIAMS, D.L.; ROBINSON, J.C.; FIELD, E.L.H. Efficacy of topical aciclovir for de treatment of feline herpetic keratitis: results of a prospective clinical trial and data from in vitro investigations.

Veterinary Record, v. 157, p. 254-257, 2005. 
